\title{
Entrevista com Ana Maria Baima Cartaxo: Previdência Social, história e contradições
}

Hélder Boska de Moraes Sarmento

Universidade Federal de Santa Catarina (UFSC)

\author{
María Del Carmen Cortizo \\ Universidade Federal de Santa Catarina (UFSC)
}

Entrevista com Ana Maria Baima Cartaxo: Previdência Social, história e contradições Interview with Ana Maria Baima Cartaxo: Social Security, history and contradictions 
Hélder e María - Por que a previdência é um tema pouco pesquisado e debatido no campo das políticas sociais e do Serviço Social?

Ana Maria ${ }^{1}$ - A Política Social Previdenciária é uma das principais políticas de proteção social ao trabalho, como enfrentamento da questão social. Coloca-se, contraditoriamente, entre a relação capital e trabalho. Isto significa que sua importância ocorre em prol do sistema capitalista como estratégia de reprodução da força de trabalho, socialização do custo desse trabalho, expansão mercantil e principalmente financeira. Por outro lado, funciona também como apaziguamento dos conflitos e, ao mesmo tempo, é fruto das lutas e reivindicações sociais e sindicais em prol ao atendimento de direitos sociais. Ela abrange a proteção do nascimento à morte, o que significa percorrer a trajetória de vida dos indivíduos, seja na fase não produtiva, produtiva ou na velhice, sendo, por isso, necessária uma intervenção profissional nos diversos espaços ocupacionais - privados e públicos - e nas diversas áreas: saúde, assistência, habitação, educação etc.

No Brasil, as primeiras iniciativas previdenciárias remontam à época do império, embora na época fosse restrita aos funcionários da coroa. O marco da política social pública no Brasil ocorreu com a Previdência, que alguns autores situam na década de 1923 com a criação das Caixas de Aposentadorias e Pensões (CAP'S), as quais eram organizadas por empresas em uma perspectiva liberal, sem o aporte financeiro direto do Estado. Outros autores, com os quais eu concordo, situam na década de 1930, precisamente a partir de 1933 com a criação dos Institutos de Aposentadorias e Pensões (IAP's), organizados por categorias profissionais e contando com o financiamento do poder público. A Previdência pública, a partir da década de 1940, inclusive com o ingresso do Serviço Social, foi se tornando naquele período o maior órgão empregador do profissional assistente social, tendo sido paulatinamente precarizado a partir da década de 1980. Isto posto significa falar de sua grande importância como política social pública. No entanto, ela é operacionalizada no interior do Instituto Nacional de Seguro Social (INSS), que substituiu, em 1990, o Instituto Nacional de Previdência Social (INPS), uma instituição extremamente hierárquica e burocratizada que, de certa forma, imprimiu durante algum tempo uma cultura internista, legalista e institucionalizada. Na previdência a ação de técnicos administrativos e de outros profissionais, está submetida a uma rigorosa prescrição legal que não é apenas das leis mais gerais e específicas, mas ainda de ordens e orientações internas, exclusivas ao funcionalismo, que se constituem como "segredos institucionais". Quase tudo é submetido ao aval de uma norma e ou de um superior hierárquico. Isto foi bastante inibidor, principalmente durante a ditadura militar. Por exemplo, havia um programa denominado Interpretação da Previdência Social, coordenado pelo Serviço Social. A dinâmica das palestras, assim como de seus participantes, teria que ser aprovada pelos órgãos de segurança nacional. Uma colega foi chamada a depor porque empreendeu uma dinâmica de grupo na qual os participantes expressavam criticamente o seu pensamento em relação à instituição previdenciária.

\section{Hélder e María - E na atualidade?}

Ana Maria - Atualmente vejo que há, em relação ao passado, um salto qualitativo no sentido da produção desses profissionais, embora seja ainda incipiente. Há uma busca dos profissionais pelos cursos de mestrado e doutorado, e nos eventos da categoria tem crescido o número de trabalhos a serem comunicados. Esta significativa mudança ocorreu, sobretudo, a partir da década de 1980 e 1990. Localizo esta mudança como um marco preponderante que ocorreu no Serviço Social no espaço da Previdência na década de 1990, quando se adentra, paradoxalmente, de forma mais contundente o neoliberalismo no Brasil. Entre as mudanças, estava a contrarreforma da previdência como prioritária no pacote estabelecido pelos órgãos multilaterais. Os assistentes sociais, numa estratégia impar, reformularam um plano de trabalho de forma democrática em uma perspectiva progressista e crítica que implicava, tanto numa aproximação com os movimentos sociais e sindicais, como na necessidade de uma sólida formação teórico-metodológica para o novo exercício profissional proposto. Isto teve grande repercussão, os profissionais buscaram supervisão com professores das universidades, às vezes pagando os próprios custos individuais. Há atualmente, apesar de todas as contradições e inúmeras dificuldades que os profissionais da previdência estão vivenciando, experiências profissionais riquíssimas que deveriam ser divulgadas. Ainda há certa inibição neste sentido.

Hélder e María - Quais as principais mudanças que a previdência teve nos últimos anos?

Ana Maria - Podemos situar as mudanças a partir das décadas de 1990-2000, tendo como parâmetro a Constituição Federal de 1988 quando a Previdência, ao lado das políticas de saúde e assistência, compôs o tripé da seguridade social. Nesse momento, o sistema de seguridade brasileira constitui-se num importante e significativo avanço no nosso sistema de proteção social. Foi a partir da seguridade social que ocorreram 
mudanças fundamentais na Previdência, tais como: a) Inclusão de novos segmentos populacionais: o segurado facultativo, aquele não remunerado pelo trabalho, como dona de casa, desempregado, estudante e síndico não remunerado; b) Equiparação, parcial, na prestação dos benefícios entre os trabalhadores urbanos e rurais. Antes de 1988 a relação entre os benefícios que eram prestados para os urbanos e rurais eram extremamente desproporcionais, com prejuízo para os últimos; c) Extensão da licença maternidade de 90 para 120 dias; d) Pensão por morte, extensiva ao marido ou companheiro da segurada, antes era devida apenas à mulher e aos filhos menores de 21 anos ou inválidos, o marido ou companheiro tinha direito somente em caso de invalidez; e) Licença paternidade de cinco dias; f) Inclusão da aposentadoria proporcional ao tempo de serviço - 25 anos para a mulher, 30 anos para o homem -, o que significou reduzir, de forma opcional, em cinco anos a aposentadoria por tempo de serviço; g) Extinção de carência para os benefícios como pensão por morte, auxílio reclusão e acidentes de qualquer natureza.

Todas essas mudanças se concretizaram em um promissor avanço da política previdenciária para a proteção ao trabalho, mas ainda teríamos muito que avançar. Há importantes contradições internas no sistema como um todo. Uma das principais refere-se ao princípio ou objetivo (conforme nomenclatura constitucional) da universalidade. A rigor a universalidade da seguridade brasileira diz respeito apenas à saúde, uma vez que a Previdência se constitui como um seguro social, o que se contrapõe diametralmente à perspectiva mais ampla da seguridade. Exceção feita somente aos segurados especiais (trabalhadores rurais, pescadores artesanais e índios) os quais não são obrigados a contribuir, mas são submetidos a um rigoroso cumprimento de normas, muitas delas alheias ao mundo do trabalho desses segurados. Embora a Constituição tenha garantido a equiparação entre os trabalhadores urbanos e rurais, em termos práticos, nem todos os benefícios que podem ser usufruídos pelos primeiros são estendidos igualmente para os segundos. A universalidade para a previdência é baseada no princípio liberal de oportunidade legal, formal a todos os cidadãos, desde que contribuam. Antes da Constituição somente poderiam contribuir trabalhadores especificados pela lei previdenciária e que, ao ingressar, tivessem uma idade inferior a 60 anos; agora "todos podem". Com relação à assistência, ela alçou o status de política pública e, conforme reza a Constituição, “a todos que dela necessitem”. Todavia, o corte seletivo é brutal. Para ter acesso ao benefício de prestação continuada (BPC) não é suficiente ter no mínimo 65 anos de idade ou ser pessoa com necessidade especial atestada por médico perito do INSS, mas a família tem que ter uma renda per capita inferior a $1 / 4$ do salário mínimo. O Estado considera, portanto, necessidade somente essa faixa de renda ou sua ausência, deixando sem atendimento muitos que necessitam. Isso expressa ainda a fragilidade do nosso sistema de proteção social que, mesmo assim, encontra-se ameaçado em um processo retroativo de mudanças a partir das décadas de 1990-2000 com as contrarreformas, principalmente com relação à Previdência Social. A década de 1990 inaugurou no Brasil as recomendações do Consenso de Washington de ajuste estrutural, estratégia de enfrentamento à crise do sistema capitalista dos países centrais. Entre os vários elementos desse ajuste no campo econômico e político, o social foi alvo privilegiado. Nesse campo destacamos a previdência. Por quê? Em razão de sua importância econômica, o que se coaduna perfeitamente com o atual estágio do sistema capitalista de dominância do capital financeiro. A previdência privada constituise em um grande campo de expansão e acumulação financeira via Seguradoras e Fundos Privados de Pensão.

Hélder e María - Por isto se fala tanto em reforma da previdência, em tantos governos?

Ana Maria - Sob a alegação de um pretenso déficit financeiro e em nome de uma propalada justiça social (um sistema único previdenciário para o funcionalismo público e os trabalhadores do setor privado), foi disseminada através da mídia a necessidade da reforma da previdência, um poderoso ardil com vistas a obter o consenso da população em prol da reforma. A primeira contrarreforma ocorreu em 15 de dezembro de 1998 , através da Emenda Constitucional n. 20, no governo Fernando Henrique Cardoso (FHC), após três anos de tramitação no Congresso Nacional da Proposta de Emenda Constitucional (PEC) n. 33 de 1995. As principais alterações foram: a) Extinção da aposentadoria proporcional ao tempo de serviço (mulher aos 25 anos de idade, homem aos 30 anos); b) Extinção da aposentadoria por tempo de serviço (mulher aos 30 anos, homem aos 35 anos) substituída por tempo efetivo de contribuição (mulher aos 30 anos, homem aos 35 anos). Convém esclarecer que para a modalidade aposentadoria por tempo de serviço, a carência, antes da Constituição, era de 5 anos, e após Constituição 15 anos. Na atual modalidade, a aposentadoria integral (o que não significa $100 \%$ do salário) requer a contribuição de todo esse tempo; c) Extinção da aposentadoria especial (25 anos) para os professores de nível superior, permanecendo apenas para os de nível básico e fundamental; d) Aposentadorias especiais restritas ao efetivo exercício em condições de riscos (químico, físico ou ergométrico) a que o trabalhador estiver exposto; e) O salário família e o auxílio-reclusão tiveram sua concessão restrita a uma baixa renda, cujo valor é determinado pelo Estado anualmente. Como o governo não conseguiu entre as mudanças aliar tempo de contribuição a uma idade mínima editou no ano seguinte, em 1999, o Fator Previdenciário, 
fórmula matemática que contém os seguintes elementos: tempo de contribuição e idade no momento do requerimento da aposentadoria; expectativa de vida a partir da aposentadoria (baseada numa tabela do IBGE); e aplicação de alíquota que aplicada ao cálculo da aposentadoria por tempo de contribuição, reduz ainda mais o seu valor conforme a idade do segurado. O funcionalismo passou a ter regras próprias: idade mínima, maior tempo de contribuição, no serviço público e na carreira na qual ocorrer a aposentadoria.

No governo Luis Inácio Lula da Silva foram empreendidas duas contrarreformas constitucionais, dirigidas mais ao funcionalismo público, através das Emendas Constitucionais n. 41/2003 e n. 47/2005. De forma geral, as mudanças foram: aumento da idade para aposentadoria por tempo de contribuição aliada à idade mínima (mulher 55 anos de idade, homem 60 anos) e mais tempo de contribuição (30 e 35 anos respectivamente); tempo no serviço público ( 25 anos, 15 anos na carreira e cinco no cargo em que se der a aposentadoria); quebra da paridade entre o funcionalismo ativo e inativo; e contribuição de 11\% (aposentados e pensionistas) sobre o valor que exceder ao teto do Regime Geral da Previdência (atualmente é de R\$4.663,75). No governo Dilma foi aprovada a PL 1992/2007, Lei 12.618 de 30 de abril de 2012, que institui o Fundo de Previdência Privada para os servidores dos três poderes, além de regulamentar, para o executivo - FUNPRESP_EXE em 20.09. 2012 -, que passou a vigorar em 01 de março de 2013. Por essa mediada os servidores ingressos terão aposentadoria e pensões no limite do teto do RGPS, devendo complementar com o Fundo privado, o que significa uma grande perda de direito.

Recentemente, fazendo parte do ajuste fiscal, foram realizados novos ataques aos direitos sociais por meio das medidas provisórias 664 e 665/2014. A primeira, transformada em Lei 13.135/2015, mudou as regras do auxílio-doença e da pensão por morte. O auxílio-doença mudou o cálculo da média de $80 \%$ dos maiores valores para as doze últimas contribuições. A pensão por morte, antes sem carência e vitalícia, passou a ter carência de 24 meses e exigência de dois anos de casado ou de união estável. Continua vitalícia apenas para os cônjuges e companheiro (a) com idade a partir de 44 anos exceto quando o segurado (a) morreu em razão de acidente de qualquer natureza, doença do trabalho ou profissional. As idades inferiores têm um escalonamento temporário de vigência do benefício conforme a idade do requerente. $\mathrm{O}$ auxílio-reclusão, antes sem carência, atualmente é de 24 contribuições e só não terá prazo de vigência se a expectativa de sobrevida do requerente no dia da prisão do segurado for de até 35 anos; se for superior, será temporário.

A segunda MP (665), transformada na Lei 13.134, trata de mudanças no seguro-desemprego, que passou a exigir que o trabalhador tenha trabalhado no mínimo 12 meses com carteira assinada nos últimos 18 meses, e será concedido em quatro parcelas em sua primeira solicitação. A regra do jogo muda conforme as solicitações seguintes e o tempo trabalhado. Isto se torna drástico considerando o atual cenário de desemprego no país. Segundo dados da Relação Anual de Informações Sociais (RAIS) de 2013 do Ministério do Trabalho, o número de desempregados sem justa causa chegou a 12,5 milhões, desse total, 3,2 milhões não teriam direito a esse benefício. Com a medida atual, segundo o DIEESE, aumentará em 8,0 milhões, ou seja, $64,4 \%$ do total de desempregados que não receberão esse seguro. A mesma Lei altera o abono salarial: antes era devido um salário mínimo aos trabalhadores de até dois salários mínimos que tivessem trabalhado pelo menos um mês no ano anterior. A partir da nova medida somente será pago àquele trabalhador que tiver trabalhado no mínimo seis meses ininterruptos no ano anterior com carteira assinada e será proporcional ao tempo trabalhado, similar ao $13^{\circ}$ salário. Outra perda de direito refere-se ao seguro do defeso, o benefício de um salário mínimo que teria direito o pescador artesanal no período em que ficava proibido de pescar. Com a nova Lei necessita comprovar três anos de trabalho e pago um ano de previdência. A perda de direitos em cascata que vem ocorrendo desde a década de 1990, aprofunda-se, com a crise atual no cenário brasileiro, mas somente para os trabalhadores.

Na outra ponta, ou seja, para os empresários ocorre o contrário, pois a Lei 12.546 de 14/12/2011 estabelece a desoneração da folha de pagamento de contribuição ao governo. Segundo dados da Receita Federal, o governo deixou de arrecadar, em 2013, R \$ 12,3 bi, e R 4.598 bilhões até março de 2014. Isso sem contar o pagamento da dívida pública aos rentistas, que atualmente está em $47 \%$.

Hélder e María - Como você analisa a relação entre a previdência e as demais políticas que compõem a seguridade social?

Ana Maria - Teoricamente e formalmente, o sistema de seguridade social brasileiro, segundo a Constituição Federal em seu Art.194, é definido como "um conjunto integrado de ações” de iniciativas dos poderes públicos e da sociedade destinados a assegurar os diretos relativos à saúde, à previdência e à assistência social. De forma geral, possui um conjunto de objetivos que são da seguridade como um todo e não apenas de uma ou de outra política entre as que compõem o tripé desse sistema. No entanto, há contradições contundentes na materialidade desses objetivos, sendo que um deles, conforme abordei, diz respeito à universalidade; o outro, que se contrapõe a universalidade, é a seletividade, que deveria ser conjugar maiores esforços e recursos para 
a população de baixa renda, mas, ao contrário, restringe o acesso apenas a esse segmento, numa variação perversa e complexa.

Outra falta de integração do sistema diz respeito ao orçamento para a Seguridade. A Constituição Federal, em seu art. 195, estabeleceu uma série de elementos importantes para compor o financiamento desse sistema: contribuições sociais; Contribuição Sobre o Lucro Líquido (CSLL); Contribuição para o Financiamento da Seguridade Social (Confins); e concurso de prognósticos e orçamento dos Ministérios das três políticas sociais. No entanto, o pagamento dos benefícios previdenciários é custeado apenas pelas contribuições sociais de trabalhadores e empregadores, ignoram-se os demais dispositivos previstos na Constituição. Segundo os preceitos constitucionais, $30 \%$ do orçamento geral da seguridade deveriam ser destinados à saúde, mas nunca foi cumprido, resultando em uma série de artefatos para custear a saúde, entre as quais foi, no passado, instituída a CPMF, destinada exclusivamente a essa política, que também não foi assim destinada. A Assistência, não obstante todo discurso do governo com o bolsa família, teve reduzido o número dos beneficiários em 2014 em 3,2\% com relação ao ano de 2013. Como garantir uma integralidade se o próprio sistema de seguridade é fatiado em seus recursos? A Desvinculação da Receita da União (DRU), instituída em 1994 com o Plano Real, encontra-se em análise por meio da PEC 87/15 para ser prorrogada até 31 de dezembro de 2023 e ter uma flexibilidade maior, de $20 \%$ para $30 \%$, o que permite ao governo dispor livremente desse percentual para outros fins alheios à seguridade social. O nosso sistema de proteção social, que sempre foi fragmentado e, portanto, muito frágil, ousou certo avanço na Constituição Federal de 1988, mas logo após sua promulgação foram soltos "balões de ensaios" que os direitos ampliados tornavam ingovernável o país, prenúncio para todo o desmonte logo a seguir.

Hélder e María - O que o Serviço Social enquanto profissão tem avaliado como fundamentais para o trabalho nesta área?

Ana Maria - O Serviço Social, no contexto do INSS, passou por mudanças fundamentais desde a sua inclusão em 1943. Marco importante foi a elaboração de um plano de trabalho, denominado Matriz Teórico Metodológica do Serviço Social na Previdência (1994), construída num processo democrático de participação, ao contrário do que comumente ocorria quando os planos eram elaborados pelas instancias superiores e chegavam na execução apenas para serem operacionalizados sem nenhuma discussão. O plano de 1994, ao colocarse na interface do projeto ético político da profissão, propôs romper com o paradigma anterior marcado por uma prática profissional conservadora e burocratizada. Considerando a hierarquização da instituição e sua rigidez burocrática, foi de fato um acontecimento inédito ainda tendo em vista a década de 1990, quando se inaugura no país o projeto neoliberal e a contrarreforma previdenciária de redução e ou extinção de direitos previdenciários. O Serviço Social, nesse âmbito, posiciona-se no sentido diametralmente oposto, mas mesmo assim, numa estratégia ímpar, esse plano foi aprovado no interior da instituição. O Serviço social deveria trabalhar numa perspectiva de contribuir para a formação crítica e consciente dos trabalhadores na luta por uma previdência de real proteção ao trabalho. Nesse sentido, três ações interligadas são consideradas fundamentais no referido plano: socialização das informações previdenciárias, que deve ultrapassar a mera orientação burocrática; fortalecimento do coletivo; e assessoria aos movimentos sociais e sindicais em matéria de previdência social. Os instrumentos e técnicas também foram reelaborados na perspectiva do método adotado.

É claro que essa proposta não foi consensual, mas tornou-se hegemônica e adquiriu densidade interrompida pelos ataques decorrentes da primeira contrarreforma previdenciária de 1998, quando o Serviço Social foi ameaçado de ser extinto da previdência Social. Intento esse não concretizado devido a uma grande mobilização dos profissionais junto aos órgãos da categoria, às centrais sindicais, aos parlamentares e até dos próprios usuários. Atualmente o Serviço Social, que depois de muita luta conseguiu abertura de concurso público, em 2009, quando foram contratados 1.350 assistentes sociais até 2013, tem sofrido constantes ataques às funções que devem ser exercidas de forma privativa e exclusiva, sendo muitas vezes requisitado para outras funções alheias as suas reais atribuições.

Hélder e María - Você vem desenvolvendo uma pesquisa nesta área. Fale um pouco disto.

Ana Maria - De acordo com a nossa pesquisa, $O$ impacto das transformações Societárias na Formação e no Exercício Profissional do Assistente Social do INSS (2010-2014), não obstante a resistência de muitos profissionais, o trabalho dos assistentes sociais está muito restrito ao preenchimento da avaliação social para os requerentes do BPC por necessidades especiais. A sua inclusão foi, sem dúvida, um grande avanço ao incluir avaliação social na avaliação médica pericial, todavia esse instrumento passou a ser quase que exclusivamente o fazer da maioria dos profissionais. É um trabalho agendado previamente e cronometrado, 
sendo exigido um número de avaliações por dia para cumprir as metas de produtividade. Cada avaliação demora em média 1 hora, então resta pouco tempo para o profissional executar outras tarefas importantes como elaborar projetos aliados à saúde do trabalhador e promover a socialização das informações previdenciárias internas e externas à instituição. A Previdência Social é muito complexa, é um jogo de xadrez em que cada benefício tem a sua peculiaridade em termos de exigências burocráticas e legais. A população em geral desconhece a complexidade dessas questões e as mudanças diárias as surpreendem. Por isso é importante que o assistente social possa prestar, de forma qualificada, essas informações à população para a formação de uma consciência crítica referente à proteção social ao trabalho, e para a organização e mobilização em prol de um sistema mais justo e igualitário. área?

Hélder e María - Quais as preocupações que você traz quanto à formação profissional para esta

Ana Maria - O objeto do Serviço Social é atuar na questão social. Considerando esse aspecto e a importância da política social no enfrentamento dessa questão, como direito da população trabalhadora à proteção social ao trabalho, penso que deveria haver em todos os currículos dos cursos de Serviço Social uma preocupação em ministrar, de forma específica, essa política como uma das disciplinas. São poucos os cursos que privilegiam o estudo dessa política. Segundo o meu conhecimento, além do Departamento de Serviço Social da Universidade Federal de Santa Catarina (UFSC), há apenas no Curso de Serviço Social da Universidade de Brasília (UnB), da Universidade Federal de Juiz de Fora (UFJF), e da Universidade Federal do Rio de Janeiro (UFRJ).

Hélder e María - Será que isto se constitui também como um dos fatores de pouca produção na área?

Ana Maria - Penso que pode ser uma das hipóteses. Considero essa disciplina de suma importância nos cursos de Serviço Social pelas razões que relatei anteriormente, como ainda, em razão de sua complexidade e transversalidade às demais políticas e espaços sócio ocupacionais. Deve se constituir para além dos aspectos legais e burocráticos nos quais se revestem a materialidade dessa política, ou seja, apreendida continuamente no movimento sócio-histórico da sociedade brasileira e mundial.

Hélder e María - Por que há avanços e recuos?

Ana Maria - Somente poderemos explicar a partir de uma rigorosa apreensão teórico- metodológica e crítica dos processos sociais nos vários momentos históricos que fazem parte da dinâmica capitalista em seus diversos estágios.

Hélder e María - Poderia indicar as principais tendências governamentais sobre a previdência no Brasil, América Latina e em outros países?

Ana Maria - A partir da década de 1970, em razão da crise do sistema capitalista, uma das estratégias de reestruturação foi realizar mudanças nos modelos de proteção social que vigoraram após os anos de 1930 e, principalmente, após a segunda guerra mundial. Nos países europeus ocidentais, o então Estado de bem-estar social (Welfare State), predominante na Inglaterra e nos países escandinavos, o Estado Providencial, na França, e o Estado Social, na Alemanha, de ampla intervenção bancada pelo poder público, entrou em crise devendo ser substituído pelo Estado misto ou pluralista, conforme alguns autores. Isso significou redução do poder público no financiamento da proteção e a abertura para o mercado e para o terceiro setor. Convém enfatizar que esses países tiveram pleno emprego e um sistema de proteção social bem mais amplo do que ocorreu com os países latino-americanos e Caribe. Na Europa a população tem reagido veementemente às mudanças no sistema previdenciário. A França não possui sistema complementar de previdência; no Reino Unido os planos de benefícios são definidos e estabelecidos por um benefício fixo e pelo nível de renda conforme cálculo da média salarial durante a vida produtiva. Com a crise do sistema os países periféricos europeus têm sofrido drásticos cortes nos benefícios previdenciários, tal como ocorre na Grécia, Portugal e Espanha, chegando, em alguns casos, a cortes de até $70 \%$ no valor das aposentadorias. Nos Estados Unidos as aposentadorias são baseadas numa fórmula progressiva, corrigidas conforme o valor do dólar e tem uma complementação variável conforme a riqueza produzida. No Canadá o benefício é universal e fixo fundamentado por uma renda suplementar.

Os países latino-americanos foram os que mais prejudicaram a população com os ajustes neoliberais. A 
mudança fundamental em termos previdenciários diz respeito ao sistema de financiamento, de regime de repartição simples, baseada na solidariedade intergeracional para o de capitalização do sistema, baseado na variação do mercado financeiro. O primeiro país a adotar as mudanças determinadas pelo Banco Mundial foi o Chile (1981), que sob o regime ditatorial de Pinochet privatizou totalmente o sistema, deixando $50 \%$ da população totalmente desprotegida, seja pela incapacidade de contribuição ou pelo alto grau de inadimplência, razão pela qual a presidenta Michelle Bachelet criou, em (2008), uma pensão básica universal fixada, inicialmente, em 60 mil pesos ( $\mathrm{R}$ \$230,00), além de um suporte previdenciário solidário para os maiores de 65 anos de idade que não conseguiram contribuição suficiente para pensão de 255 pesos mil pesos (R\$ 978). No México, o Instituto Mexicano de Seguro Social, fundado em 1943, era baseado no sistema de repartição simples. Com a reforma em 1997 optou por um sistema misto que inclui o regime de capitalização. O sistema do Uruguai também, desde 1960, era baseado no princípio da solidariedade intergeracional e, neste sentido, também teve mudanças. A Argentina empreendeu a reforma no ano de 1993 com o governo Carlos Menem, que instituiu o sistema integrado de "Jubilaciones e Pensiones" através das Administradoras Privadas, processo revertido a partir do governo de Nestor Kischner em razão da desproteção social da população em termos previdenciários e a recuperação parcial da crise que assolou o país. No que pese as contrarreformas sob as diversas justificativas oficiais, o que está em jogo é a possibilidade via privatização da previdência enriquecer o mercado financeiro através dos Fundos e Seguradoras Privadas de Pensões.

Hélder e María - Para finalizar, poderia indicar alguns desafios para os profissionais e pesquisadores que se dedicam à previdência social?

Ana Maria - Para os profissionais, de forma geral, um dos desafios é estudar e acompanhar as mudanças na Previdência Social brasileira em razão de sua importância para a população usuária que demanda, dos profissionais, conhecimento dessa política em qualquer espaço sócio ocupacional. Particularmente, para os profissionais que trabalham diretamente com essa política os desafios são bem maiores, quer em razão das dificuldades encontradas no interior da própria instituição previdenciária - que requer ações, muitas das quais, alheias às privativas e exclusivas do profissional assistente social -, quer pelas exigências de cumprimento de metas e produtividade em detrimento de outras ações de extrema importância, como a socialização das informações previdenciárias inter e extra instituição. Além disso, é de fundamental importância a constante apreensão do movimento dessa política na atual conjuntura de retrocesso e de extinção dos direitos sociais previdenciários, entre outros. Para isso, exige uma formação continuada que possibilite apreensão rigorosa e sólida dos processos sociais para o estabelecimento de estratégias interventivas de enfrentamento, pesquisa e socialização desse conhecimento acumulado. Para os pesquisadores em políticas sociais, acredito que seria importante ampliar o número de pesquisas acerca dessa política.

\section{Nota}

1 Ana Maria Baima Cartaxo é Professora Doutora da Universidade Federal de Santa Catarina (UFSC), dedicando-se ao tema da Previdência Social, comênfase em Serviço Social. Possui vários artigos sobre Política previdenciária, Serviço Social, Prática profissional, Seguridade social e Política previdenciária e Serviço Social.

\section{Hélder Boska de Moraes Sarmento}

hboska@yahoo.com.br

Doutor em Serviço Social pela Pontifícia Universidade Católica de São Paulo

Professor do Departamento de Serviço Social (DSS) e do Programa de Pós-Graduação em Serviço Social na Universidade Federal de Santa Catarina (PPGSS-UFSC)

\section{María Del Carmen Cortizo}

mariac@cse.ufsc.br

Doutora em Ciências Sociais pela Universidade Estadual de Campinas

Professora do Departamento de Serviço Social (DSS) e do Programa de Pós-Graduação em Serviço Social na Universidade Federal de Santa Catarina (PPGSS-UFSC) 
UFSC - Programa de Pós-Graduação em Serviço Social

Campus Universitário Reitor João David Ferreira Lima

Bairro Trindade

Florianópolis - Santa Catarina - Brasil

CEP: 88040-970 